DOI: https://doi.org/10.24127/ajpm.v10i2.3442

\title{
SOAL HIGHER ORDER THINKING SKILLS (HOTS) MATEMATIKA PADA BUKU TEMATIK TERPADU KURIKULUM 2013
}

\author{
Norma Dewi Shalikhah $^{1^{*}}$, Arif Wiyat Purnanto ${ }^{2}$, Irham Nugroho ${ }^{3}$ \\ ${ }^{1 *}, 3$ Pendidikan Guru MI, Universitas Muhammadiyah Magelang, Indonesia \\ ${ }^{2}$ Pendidikan Guru SD, Universitas Muhammadiyah Magelang, Indonesia \\ * Universitas Muhammadiyah Magelang, Indonesia \\ E-mail: $\quad$ normadewi@ummgl.ac.id ${ }^{\left.{ }^{*}\right)}$ \\ arifwiyatumm@gmail.com ${ }^{2)}$ \\ irham_nugroho@ummgl.ac.id ${ }^{3)}$
}

Received 30 December 2020; Received in revised form 26 June 2021; Accepted 28 June 2021

\begin{abstract}
Abstrak
Rendahnya kemampuan siswa dalam memecahkan masalah dapat diatasi salah satunya dengan terbiasa mengerjakan soal berbasis berpikir tingkat tinggi atau Higher Order Thinking Skills (HOTS) yang meliputi menganalisis (C4), mengevaluasi (C5) dan menciptakan (C6). Penelitian ini bertujuan mengetahui persebaran soal Matematika berbasis HOTS pada buku ajar tematik terpadu kurikulum 2013. Urgensinya untuk memberikan gambaran kepada pemerintah khususnya para guru terkait kualitas buku tersebut yang ada di sekolah yang masih digunakan sampai tahun 2021 ini . Penelitian ini merupakan penelitian analisis isi (content analysis) dengan pendekatan kualitatif. Sumber data dalam penelitian ini adalah buku ajar tematik terpadu Kurikulum 2013 edisi revisi 2018 kelas I sampai III SD/MI. Teknik analisis data menggunakan teknik analisis persentase. Hasil penelitian menunjukkan tingkat kognitif soal HOTS kelas I aspek C4 sebesar 22\%, C5 sebesar 4\%, C6 sebesar 11\%. Kelas II, C4 sebesar 28\%, C5 sebesar 1\%, C6 sebesar 6\%. Sedangkan kelas III, C4 sebesar 29\%, C5 sebesar 3\%, C6 sebesar 6\%. Kesimpulannya soal HOTS matematika tingkat kognitif C4, C5, dan C6 pada buku tematik kurikulum 2013 kelas I, II, dan III belum mencapai kriteria soal yang baik karena persentase soal yang baik untuk masing-masing tingkat kognitif C4 sebesar 40\%, C5 sebesar 30\%, dan C6 sebesar $30 \%$.
\end{abstract}

Kata kunci: Buku tematik; HOTS; soal matematika.

\begin{abstract}
Low ability of students solving the problems can be overcome by accustomed to work on Higher Order Thinking Skills (HOTS) which include analyzing (C4), evaluating (C5) and creating (C6). This study aims to find the distribution of Mathematics questions based on HOTS in integrated thematic textbooks in the 2013 curriculum. Its importance is to give an overview to the government, especially teachers about the quality of these books which are used by schools until 2021. This research is a content analysis with a qualitative approach. Data sources in this study are integrated thematic textbooks of Curriculum 2013 revised edition 2018 for grades I to III SD / MI. The data analysis technique uses percentage analysis. The results showed that the cognitive level of HOTS class I in C4 at 22\%, C5 at 4\%, C6 at 11\%. Class II, C4 at 28\%, C5 at 1\%, C6 at 6\%. Meanwhile, class III, C4 at 29\%, C5 at 3\%, C6 at 6\%. In conclusion, HOTS mathematics questions on cognitive level C4, C5, and C6 in the thematic books of the 2013 curriculum for classes I, II, and III have not reached the criteria for good questions because the percentage of good questions for each cognitive level is C4 $40 \%$, C5 $30 \%$, and C6 by $30 \%$.
\end{abstract}

Keywords: Thematic book; HOTS; mathematics question.

This is an open access article under the Creative Commons Attribution 4.0 International License

\section{PENDAHULUAN}

Revolusi

Industri $\quad 4.0$

mengharuskan sekolah menghasilkan

lulusan yang hafal berbagai bahan sekaligus memiliki keterampilan berpikir kritis (Kamil, Velina, \& Kamelia, 2019). Rendahnya kemampuan siswa dalam memecahkan masalah 
dapat diperbaiki dengan memberikan latihan soal-soal Higher Order Thinking Skills (HOTS) (Haniffah, 2014). Berdasarkan Permendikbud nomor 64 tahun 2013 tentang standar isi, HOTS merupakan salah satu prioritas yang dikembangkan khususnya dalam pelajaran matematika. Pembelajaran matematika dengan penggunaan soal HOTS yang menuntut siswa untuk berpikir kritis sangat tepat untuk diimplementasikan pada jenjang SD/MI (Wardhani, 2018).

Beberapa penelitian yang berkaitan dengan soal HOTS Matematika SD adalah (Amelia, 2016) dan (Nursyifa, 2020), namun hanya mengkaji satu materi dan satu jenjang kelas. Penelitian lain mengkaji pengembangan soal HOTS Matematika (Rahayu, 2020), (Rohim, 2019), dan (Lestari, Saepulrohman, \& Hamdu, 2016). Sedangkan dalam penelitian ini menganalisis soal HOTS Matematika kelas I, II, dan III SD/MI yang terdapat pada buku tematik terpadu kurikulum 2013 edisi revisi 2018. Hal inilah yang merupakan keterbaruan dari penelitian karena mengembangkan penelitian yang sebelumnya yang mana hanya menganalisis soal dalam satu materi saja, dan juga akan terkait dengan penelitian tentang pengembangan soal HOTS.

Penelitian ini penting dilakukan karena untuk mengetahui sebaran soal HOTS, agar siswa terbiasa mengerjakan soal-soal yang butuh mengembangkan daya nalar dan berpikir kritis. Temuan di lapangan, hasil Ujian Nasional tahun 2018 yaitu siswa masih lemah dalam menalar, menganalisa, dan mengevaluasi yang menunjukkan rendahnya keterampilan berpikir tingkat tinggi pada siswa (Setiawati, 2019). Tidak semua soal Ujian Sekolah Berstandar Nasional (USBN) tahun pelajaran 2017/2018 kriteria HOTS C4, C5, C6 terpenuhi, sedangkan pada tahun pelajaran 2018/2019 soal komponen kriteria HOTS C4, C5, C6 terpenuhi namun persentase nya belum memenuhi kriteria soal HOTS yang baik (Aprilliani, Kusmaryono, \& Wijayanti, 2019). Berdasarkan hasil TIMSS (Trends in International Mathematics and Science Study), posisi Indonesia pada domain kognitif dan domain konten bilangan masing-masing berada pada peringkat 37 dari 43 negara (Wangge, 2016). Sedangkan menurut hasil Programme for International Student Assessment (PISA) tahun 2018, kemampuan siswa Indonesia dalam membaca, matematika, dan sains menurun dibandingkan pada tahun 2015 dengan peringkat 71 dari 78 negara (Avvisati, 2019). Beberapa permasalahan tersebut menunjukan bahwa kemampuan siswa pada aspek penalaran rendah, dikarenakan kurang tersedianya soal-soal berbasis HOTS, soal-soal tes yang dibuat tidak semuanya mengacu pada HOTS, sehingga siswa kurang dilatih dalam mengembangkan kemampuan berpikir tingkat tinggi.

Upaya untuk mengurangi permasalahan di atas adalah memperbanyak soal-soal berbasis HOTS, soal-soal ujian mengacu pada HOTS, dan melakukan pembelajaran berbasis HOTS. Tujuan dari penelitian ini untuk mengetahui persebaran soal Matematika berbasis HOTS pada buku ajar tematik terpadu kurikulum 2013 kelas I, II, dan III SD/MI berdasarkan Taksonomi Bloom Revisi, sehingga dapat sebagai acuan pentingnya penambahan soal HOTS atau pengembangan soal HOTS pada buku ajar tematik SD/MI. 
DOI: https://doi.org/10.24127/ajpm.v10i2.3442

\section{METODE PENELITIAN}

Jenis penelitian ini adalah analisis isi (content analysis) dengan pendekatan kualitatif yang bertujuan menganalisis tingkat kognitif soal HOTS matematika pada buku ajar tematik kurikulum 2013 SD/MI berdasarkan ranah kognitif taksonomi Bloom Revisi dan disesuaikan dengan kriteria soal yang baik. Teknik pengumpulan data yaitu dengan metode dokumentasi yang digunakan untuk mengumpulkan data penelitian berdasarkan indikator dari tingkatan kognitif taksonomi Bloom. Adapun indikator tingkat kognitif untuk mengukur soal HOTS ditampilkan pada Tabel 1.

Tabel 1. Penentuan tingkat kognitif soal HOTS

\begin{tabular}{cl}
\hline $\begin{array}{c}\text { Tingkat } \\
\text { Kognitif }\end{array}$ & \multicolumn{1}{c}{ Indikator } \\
\hline C4. & Menggunakan kata \\
Menganalisis & kerja operasional \\
& membedakan, \\
& membandingkan, \\
& mengorganisir, atau \\
& menghubungkan. \\
& Kemampuan \\
& memisahkan konsep \\
& ke beberapa \\
& komponen dan \\
& mnghubungkannya \\
& untuk memperoleh \\
& pemahaman atas \\
& konsep tersebut. \\
& Menggunakan kata \\
& kerja operasional \\
& menyeleksi, \\
& mempertahankan, \\
C5. & menilai, \\
menjustifikasi, & mengkritik, \\
& memprediksi, \\
& membenarkan, atau \\
& menyalahkan. \\
&
\end{tabular}

\begin{tabular}{cl}
\hline Tingkat & \multicolumn{1}{c}{ Indikator } \\
Kognitif & \multicolumn{1}{c}{ Kemampuan } \\
& menetapkan sesuatu \\
& berdasarkan kriteria \\
& tertentu. \\
C6. & Menggunakan kata \\
Mencipta & kerja operasional \\
& merancang, \\
& menemukan, \\
& menciptakan, \\
& mengembangkan,me \\
& lengkapi, membuat, \\
& mendisain, atau \\
& menghasilkan karya. \\
& Kemampuan \\
& memadukan unsur- \\
& unsur menjadi \\
& sesuatu bentuk baru \\
& atau membuat \\
& sesuatu yang orisinil.
\end{tabular}

(Sofyatiningrum, Sisdiana, \& Astuti, 2018)

Variabel dalam penelitian ini adalah tingkat kognitif soal HOTS berupa $\mathrm{C} 4$ (menganalisis), C5 (mengevaluasi), dan C6 (mencipta) mata pelajaran Matematika pada buku tematik K2013 kelas I, II, dan III SD. Subjek penelitian ini adalah soal-soal matematika pada buku ajar tematik terpadu Kurikulum 2013 edisi revisi 2018 kelas I sampai III SD terbitan Kemendikbud yang berjumlah 543 .

Prosedur penelitian terdiri dari beberapa langkah yaitu sebagai berikut:

1) Menyiapkan buku tematik kurikulum 2013 SD/MI revisi terbaru.

2) Memilah buku tematik yang terdapat soal matematika.

3) Memilah soal-soal matematika pada setiap kelas.

4) Menganalisis soal-soal matematika HOTS dan bukan HOTS berdasarkan Taksonomi Bloom Revisi. 
5) Mengklasifikasi dan menganalisis soal HOTS berdasarkan tingkat kognitif C4 (menganalisis), C5 (mengevaluasi), dan C6 (mencipta) sesuai Taksonomi Bloom Revisi.

6) Data hasil evaluasi kernudian ditabulasikan dalam tabel.

7) Menghitung presentase kriteria soal tipe HOTS.

8) Memberikan kesimpulan terkait kualitas dari soal matematika berbasis HOTS pada buku tematik terpadu kurikulum 2013.

Analisis data dalam penelitian ini adalah sebagai berikut:

1) Analisis soal berdasarkan Taksonomi Bloom Revisi.

2) Mengklasifikasikan soal berdasarkan tingkat kognitif Taksonomi Bloom Revisi

3) Menghitung presentase tingkat kognitif pada soal matematika berdasarkan Taksonomi Bloom Revisi dengan menggunakan rumus:

$$
\mathrm{Pi}=\frac{N i}{N} \times 100 \%
$$

Keterangan:

$\mathrm{Pi}=$ Presentase banyaknya soal yang dikategorikan dalam tingkat kognitif (C4, C5, dan C6)

$\mathrm{Ni}=$ Jumlah soal yang dikategorikan dalam tingkat kognitif (C4, C5, dan C6)

$\mathrm{N}=$ Jumlah semua soal yang diamati

\section{HASIL DAN PEMBAHASAN}

Sebagian besar guru mengetahui level kognitif taksonomi Bloom tetapi mereka belum mengetahui perbedaan dan fungsi masing-masing level dalam taksonomi Bloom tersebut. Guru matematika masih belum memiliki pengetahuan mendalam tentang HOTS dari aspek penilaian dan hal ini bisa berdampak pada proses implementasi pembelajaran matematika berbasis HOTS di sekolah (Abdullah, 2017). Kendala dalam mengimplementasikan HOTS pada kegiatan pembelajaran, sebagian besar saat merancang evaluasi (Rapih \& Sutaryadi, 2018). Jika guru belum paham tentang soal HOTS, guru akan kesulitan menganalisis buku pegangan yang selama ini digunakan di sekolah apakah sudah mengandung unsur HOTS, yang nantinya akan dikembangkan dalam proses pembelajaran maupun asessment. Buku pegangan guru sekolah dasar selama ini menggunakan terbitan Kemendikbud yaitu buku tematik kurikulum 2013.

Usaha peningkatan kemampuan berpikir tingkat tinggi atau HOTS pada siswa dapat dilaksanakan melalui kegiatan penilaian hasil belajar sehingga diharapkan dapat mendorong berpikir secara luas dan mendalam tentang materi pelajaran. HOTS merupakan bagian dari taksonomi Bloom hasil revisi yang berupa kata kerja operasional yang terdiri dari analyze (C4), evaluate (C5) dan create (C6) yang dapat digunakan dalam penyusunan soal (Fanani, 2018). Pemikiran tingkat tinggi pada siswa terjadi ketika siswa memperoleh pengetahuan baru dan menyimpannya dalam memori sehingga pengetahuan ini berkorelasi dengan pengetahuan sebelumnya untuk mencapai tujuan tertentu (Abosalem, 2016). Pada pemikiran tingkat tinggi, siswa akan cenderung menggunakan logika daripada hanya mengingat dan menghafal rumus sehingga siswa akan menguasai konsep dan dapat memecahkan masalah matematika yang lebih kompleks (Nurina, 2015).

Semua siswa mulai dari sekolah dasar perlu mendapatkan pelajaran 
Matematika untuk melatih daya pikir kritis, logis, analitis, kreatif, dan kemampuan pemecahan masalah dalam kehidupan sehari-hari. Sehingga dibutuhkan bimbingan guru untuk membiasakan siswa berlatih menganalisa, mengemukakan pendapat, memberikan penilaian, dan memecahkan masalah.

Keterampilan berpikir kritis dapat dilatih dalam pembelajaran matematika yang salah satu pelaksanaannya menggunakan bahan ajar seperti buku teks. HOTS merupakan salah satu tujuan utama dalam pendidikan dan menjadi salah satu dari lima variabel teratas yang dapat meningkatkan prestasi belajar siswa. Buku teks adalah salah satu media pembelajaran yang dapat digunakan dalam melatih HOTS karena buku teks media pembelajaran utama guru dan siswa (Pratama, 2018). Keputusan guru dalam memilih bahan dan strategi pengajaran juga secara langsung diperoleh oleh buku teks yang digunakan oleh guru.

Buku Ajar Tematik Kurikulum 2013 SD/MI terbitan Kementerian Pendidikan dan Kebudayaan kelas I, II, IV, V revisi terbaru tahun 2017, sedangkan kelas III dan VI revisi terbaru 2018. Kelas I, II, dan III terdiri dari 8 tema dengan masing-masing tema terdiri dari 4 subtema, sedangkan kelas IV, V, dan VI terdiri dari 9 tema dengan masing-masing tema terdiri dari 3 subtema. Pada penelitian ini hanya menganalisis tingkat kognitif HOTS mata pelajaran matematika SD/MI kelas 1, II, dan III karena di kelas IV, V, dan VI soal matematika hanya ada di semester 1 sedangkan di semester 2 pada buku tematik tidak ada soal matematika, sehingga menjadi kekurangan dari penelitian ini.

Pada buku tematik kurikulum 2013 kelas I, II, dan III ini memuat 543 butir soal matematika dengan jumlah masing-masing kelas I sebanyak 166 butir soal, kelas II sebanyak 187 butir soal, dan kelas III sebanyak 190 butir soal. Jumlah keseluruhan soal HOTS mata pelajaran matematika adalah 199 butir soal yaitu dengan sebaran kelas I sebanyak 62 butir soal (37\%), kelas II sebanyak 65 butir soal (35\%), dan kelas III sebanyak 72 butir soal (38\%). Jika dalam bentuk presentase, soal HOTS $37 \%$, soal bukan HOTS $63 \%$ seperti yang disajikan pada gambar 1 sebagai berikut.

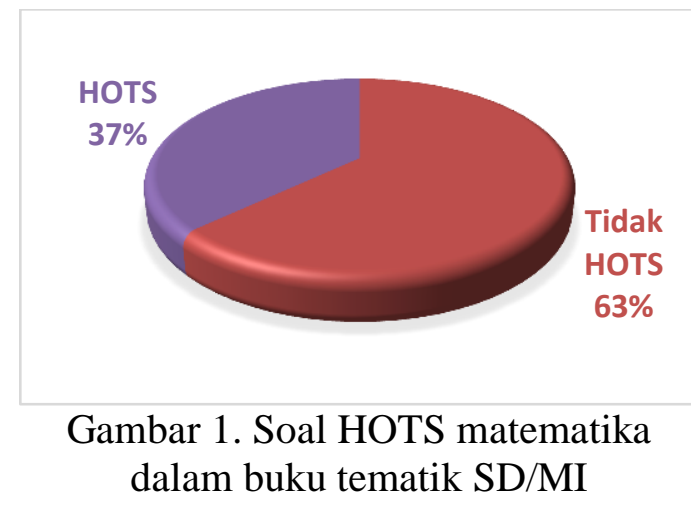

Berdasarkan gambar 1 tersebut menunjukkan sebaran soal HOTS masih terlalu sedikit karena di bawah 50\% sehingga perlu ada penambahan soalsoal HOTS pada buku ajar tematik. Hal ini sesuai dengan penelitian (Rahayu, 2020), (Rohim, 2019), dan (Lestari et al., 2016) yaitu perlunya pengembangan soal-soal Matematika berbasis HOTS.

Secara rinci setiap tingkatan kognitif yaitu tingkat kognitif C4 (analisis) soal matematika sejumlah 144 butir soal dengan sebaran di kelas I sebanyak 37 butir soal, kelas II sebanyak 52 butir soal, dan kelas III sebanyak 55 butir soal. Tingkat kognitif C5 (evaluasi) soal matematika sejumlah 14 butir soal dengan sebaran di kelas I sebanyak 6 butir soal, kelas II sebanyak 2 butir soal, dan kelas III sebanyak 6 butir soal. Sedangkan tingkat kognitif 
C6 (mencipta) soal matematika sejumlah 41 butir soal dengan sebaran di kelas I sebanyak 19 butir soal, kelas II sebanyak 11 butir soal, dan kelas III sebanyak 11 butir soal. Jumlah soal HOTS matematika pada tingkat kognitif C4, C5, dan C6 disajikan pada tabel 2 sebagai berikut.

Tabel 2. Jumlah tingkat kognitif soal HOTS matematika

\begin{tabular}{cccccc}
\hline No & HOTS & I & II & III & Jumlah \\
\hline 1 & C4 & 37 & 52 & 55 & 144 \\
2 & C5 & 6 & 2 & 6 & 14 \\
3 & C6 & 19 & 11 & 11 & 41 \\
\hline
\end{tabular}

Sedangkan persentase tingkat kognitif C4, C5, dan C6 terhadap keseluruhan soal matematika pada setiap kelas adalah kelas I untuk $\mathrm{C} 4$ sebesar 22\%, C5 sebesar 4\%, C6 sebesar $11 \%$. Kelas II, C4 sebesar $28 \%$, C5 sebesar 1\%, C6 sebesar 6\%. Sedangkan kelas III, C4 sebesar 29\%, C5 sebesar 3\%, C6 sebesar 6\% seperti yang disajikan pada Gambar 2.

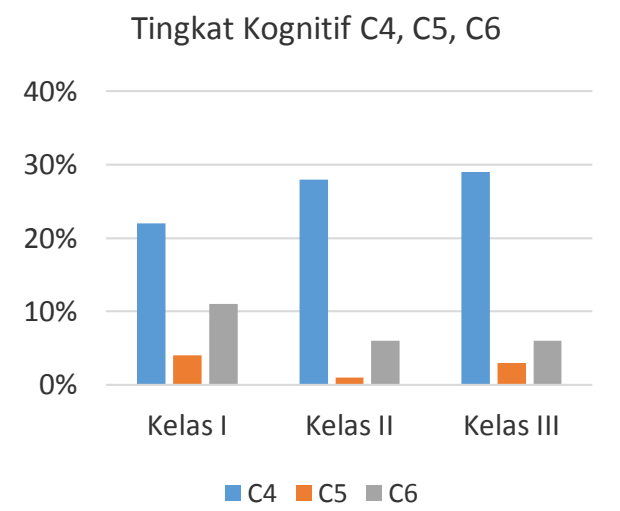

Gambar 2. Persentase Tingkat Kognitif C4, C5, dan C6

Berdasarkan Gambar 2, terlihat sebaran masing-masing tingkatan kognitif C4, C5 C6 masih di bawah $50 \%$ artinya soal-soal masih banyak yang termasuk kategori bukan HOTS karena berada di cakupan mengetahui
(C1), memahami (C2), dan menerapkan (C3). Soal-soal yang ada kebanyakan mengukur kemampuan pemahaman, menerapkan pengetahuan faktual dan konseptual. Hal tersebut mengakibatkan kemampuan berfikir siswa lemah dalam menalar, menganalisa, dan mengevaluasi, yang berdampak pada rendahnya hasil nilai Ujian Nasional (Setiawati, 2019).

Kriteria soal yang baik adalah memiliki perbandingan soal mudah, sedang, dan sulit sebesar 3:4:3 (Sudjana, 2017). Tingkat kesulitan soal berdasarkan praktiknya mengikuti aspek kognitif taksonomi Bloom. Soal kategori mudah akan dikembangkan berdasarkan tingkat kemampuan kognitif mengetahui (C1) dan memahami (C2). Soal kategori sedang dikembangkan dari tingkat kemampuan menerapkan (C3) dan menganalisis (C4). Sedangkan soal berkategori sukar dikembangkan dari tingkat kemampuan evaluasi (C5) atau mencipta (C6) (Giani, Zulkardi, \& Hiltrimartin, 2015). Sehingga persentase soal untuk masing-masing tingkat kognitif $\mathrm{C} 1$ dan C2 sebesar 30\%, C3 dan C4 sebesar 40\%, dan C5 dan C6 sebesar 30\%.

Berdasarkan hasil penelitian soal HOTS matematika tingkat kognitif $\mathrm{C} 4$, C5, dan C6 pada buku tematik kurikulum 2013 kelas I, II, dan III belum mencapai kriteria soal yang baik. Untuk mencapai kriteria soal yang baik kekurangannya adalah kelas I, tingkat kognitif C4 kurang 18\%, C5 kurang $26 \%$, C6 kurang 19\% dengan total kekurangan . Kelas II, C4 kurang 12\%, C5 kurang 29\%, C6 kurang 24\%. Kelas III, C4 kurang 11\%, C5 kurang 27\%, C6 kurang $24 \%$.

Dengan hasil analisa tingkat kognitif soal HOTS yang belum memenuhi kriteria, mengakibatkan kemampuan berpikir siswa dalam hal 
menalar, menganalisis, dan mengevaluasi lemah sehingga berdampak pada kurang kritis dan terampilnya siswa dalam memecahkan masalah dalam kehidupan sehari-hari.

Adapun solusi agar siswa terbiasa berpikir kritis yaitu 1) dengan memberikan soal - soal non rutin atau open ended problem (Hidayati, 2017). Guru harus terampil megembangkan soal-soal terbuka untuk dapat mengembangkan keterampilan berpikir tingkat tinggi pada siswa. Guru dapat memberikan soal yang menarik dan menantang agar tumbuh rasa ingin tahu dan ide-ide kreatif siswa sehingga siswa akan menilai dan menyikapinya secara kritis (Hidayati, 2017). 2) Jika guru belum bisa mengembangkan soal HOTS, perlu pelatihan atau pendampingan dalam mengembangkan soal HOTS. Dukungan untuk guru ketika merancang pertanyaan matematika akan sangat penting karena banyak guru tidak mampu mengembangkan pertanyaan matematika yang dapat melatih siswa untuk mencapai keterampilan berpikir tingkat tinggi (Wahyuni, 2018). 3) Dibutuhkan kreativitas guru dalam metode pembelajaran agar menuju pembelajaran berbasis HOTS. Perlu adanya praktik atau pelatihan karena pengetahuan saja tidak akan membatu proses implementasi HOTS dalam pembelajaran matematika (Abdullah, 2017). 4) Persiapan yang lebih dalam menyiapkan instrumen soal yang berkaitan dengan kehidupan sehari-hari siswa. Sehingga harapannya siswa di Indonesia memiliki kemampuan dalam pemecahan masalah dan berpikir krits dapat bersaing dengan negara lain.

Berdasarkan hasil penelitian ini, harapannya ada penambahan atau pengembangan soal-soal Matematika berbasis HOTS pada buku ajar tematik siswa SD/MI. Selain itu para pendidik juga dapat mengembangkan proses pembelajaran di kelas yang berbasis HOTS.

\section{KESIMPULAN DAN SARAN}

Kesimpulan dari penelitian ini adalah soal matematika pada buku ajar tematik belum memenuhi kriteria soal HOTS yang baik. Jumlah keseluruhan soal HOTS mata pelajaran matematika adalah 199 butir soal dari 543 soal keseluruhan, jika dalam bentuk presentase, soal HOTS 37\%, soal bukan HOTS 63\%. Masing-masing sebaran soal HOTS di kelas I sebanyak 37\%, kelas II sebanyak 35\%, dan kelas III sebanyak $38 \%$. Sedangkan tingkat kognitif soal HOTS kelas I aspek C4 sebesar 22\%, C5 sebesar 4\%, C6 sebesar $11 \%$. Kelas II, C4 sebesar 28\%, C5 sebesar 1\%, C6 sebesar 6\%. Kelas III, C4 sebesar 29\%, C5 sebesar 3\%, C6 sebesar 6\%. Dari hasil analisa tersebut, soal HOTS kurang dari $50 \%$ artinya soal-soal tersebut masih banyak yang termasuk kategori bukan HOTS karena berada di cakupan mengetahui (C1), memahami (C2), dan menerapkan (C3).

Saran untuk penelitian selanjutnya yaitu perlu pengembangan soal-soal berbasis HOTS pada buku pegangan pokok siswa, soal-soal ujian, dan memberikan pelatihan bagi guru dalam menciptakan pembelajaran berbasis HOTS.

\section{DAFTAR PUSTAKA}

Abdullah, A. H. (2017). Mathematics Teachers ' Level of Knowledge and Practice on the Implementation of Higher-Order Thinking Skills ( HOTS ). EURASIA Journal of Mathematics Science and Technology Education, 13(1), 317.

https://doi.org/10.12973/eurasia.20 $17.00601 \mathrm{a}$ 
Abosalem, Y. (2016). Assessment Techniques and Students ' HigherOrder Thinking Skills. International Journal of Secondary Education, 4(1), 1-11. https://doi.org/10.11648/j.ijsedu.20 160401.11

Amelia, M. A. (2016). Analisis Soal Tes Hasil Belajar High Order Thinking Skills (HOTS) Matematika Materi Pecahan untuk Kelas 5 Sekolah Dasar. Jurnal Penelitian (Edisi Khusus PGSD), 20(2), 123-131.

Aprilliani, S. E., Kusmaryono, I., \& Wijayanti, D. (2019). Analisis Soal Tipe Higher Order Thinking Skills (HOTS) pada USBN Matematika SD Tahun Pelajaran 2017/2018 dan 2018/2019. In Konferensi Ilmiah Mahasiswa Unissula (Vol. 4, pp. 1541-1552).

Avvisati, F. (2019). Progamme For International Student Assessment (PISA) Result from PISA 2018. OECD , 1-III, 1-10.

Fanani, M. Z. (2018). Strategi Pengembangan Soal Higher Order Thinking Skill (HOTS) dalam Kurikulum 2013. EDudeena: Journal of Islaic Religious Education, II(1), 57-76.

Giani, Zulkardi, \& Hiltrimartin, C. (2015). Analisis Tingkat Kognitif Soal-Soal Buku Teks Matematika Kelas VII Berdasarkan Taksonomi Bloom. Jurnal Pendidikan Matematika, 9(2).

Haniffah, D. (2014). Identifikasi Tipe dengan Soal Higher Order Thinking (HOT) Ditinjau Berdasarkan Kemampuan Matematika. MATHEdunesa: Jurnal Ilmiah Pendidikan Matematika, 3(3), 40-46.

Hidayati, A. U. (2017). Melatih Keterampilan Berpikir Tingkat Tinggi dalam Pembelajaran
Matematika pada Siswa Sekolah Dasar. Jurnal Pendidikan Dan Pembelajaran Dasar, 4(2), 143156.

Kamil, B., Velina, Y., \& Kamelia, M. (2019). Students , Critical Thinking Skills in Islamic Schools: The Effect of ProblemBased Learning ( PBL ) Model. Tadris: Jurnal Keguruan Dan Ilmu Tarbiyah, 4(1), 77-85. https://doi.org/10.24042/tadris.v4i1 .4212

Lestari, A., Saepulrohman, A., \& Hamdu, G. (2016). Pengembangan Soal Tes Berbasis HOTS pada Model Pembelajaran Latihan Penelitian di Sekolah Dasar. Pedadidaktika: Jurnal Ilmiah Pendidikan Guru Sekolah Dasar, 3(1), 74-83.

Nurina, D. L. (2015). The Effectiveness Using Problem Posing Approach and Open-Ended Approach in Terms of the HOTS. PYTHAGORAS: Jurnal Pendidikan Matematika, 10(2), 129-136.

Nursyifa, H. S. (2020). Analisis Soal HOTS Materi Geometri dalam Buku Teks Matematika Kelas IV SD. PEDADIDAKTIKA: Jurnal Ilmiah Pendidikan Guru Sekolah Dasar, 7(4).

Pratama, G. . (2018). Urgency of Higher Order Thinking Skills ( HOTS ) Content Analysis in Mathematics Textbook. Journal of Physics: Conference Series, 1097, 1-8.

Rahayu, S. (2020). Pengembangan Soal High Order Thinking Skill untuk Meningkatkan Kemampuan Berpikir Tingkat Tinggi Matematika Siswa Sekolah Dasar. PEDADIDAKTIKA: Jurnal Ilmiah Pendidikan Guru Sekolah Dasar, 7(2). 
Rapih, S., \& Sutaryadi. (2018). Perpektif Guru Sekolah Dasar terhadap Higher Order Tinking Skills ( HOTS ): Pemahaman, Penerapan dan Hambatan. Premiere Educandum, 8(1), 78-87. https://doi.org/10.25273/pe.v8i1.25 60

Rohim, D. C. (2019). Strategi Penyusunan Soal Berbasis HOTs pada Pembelajaran Matematika SD. Briliant: Urnal Riset Dan Konseptual, 4(4), 436-446.

Setiawati, W. (2019). Buku Penilaian Berorientasi Higher Order Thinking Skills. Jakarta: Kemendikbud.

Sofyatiningrum, E., Sisdiana, E., \& Astuti, R. (2018). Muatan HOTs pada PEmbelajaran Kurikulum 2013 Pendidikan Dasar. Pusat PEnelitian Kebijakan Pendidikan dan Kebudayaan, Badan Penelitian dan Pengembangan, Keenterian Pendidikan dan Kebudayaan.

Sudjana, N. (2017). Penilaian Hasil Proses Belajar Mengajar (21st ed.). Bandung: PT Remaja Rosdakarya.
Wahyuni. (2018). Teachers' Activities During Designing Higher-Order Thinking Skills ( HOTS ) Mathematical Questions Through Teacher Assisting Program. Journal of Physics: Conference Series, 1088, 1-7.

Wangge, M. (2016). Higher Order Thinking Skills (HOTS) Matematics untuk Mendukung Pembentukan Karakter Siswa. Prosiding Seminar Nasional, 1, 450-456.

Wardhani, D. A. (2018). Penggunaan Soal Higher Order Thinking Skill (HOTS) Berbasis Warisan Budaya Indonesia dalam Kurikulum 2013 dalam Melatih Kemampuan Berpikir Kritis Matematika Siswa Sekolah Dasar. In Seminar Nasional PGSD UNIKAMA (Vol. 2, pp. 32-39). 